\title{
USE OF INFOGRAPHICS BY STUDENTS IN BUSINESS DEGREES
}

\author{
B. de-Miguel-Molina, M. de-Miguel-Molina, V. Santamarina-Campos, \\ M.A. Carabal-Montagud \\ Universitat Politècnica de València (SPAIN)
}

\begin{abstract}
This paper presents the introduction of infographics in two courses during the academic year 2020-2021. These courses are from bachelor's studies in a Business School. This type of visualization was used by students as a support for summarizing and communicating their ideas. To do it, different tasks were designed, and some applications were tried by students. The experiences explained include the learning objectives that were established, the activities designed, and the pros and cons of the applications used.
\end{abstract}

Keywords: Communication, infographics, business degrees, STEAM.

\section{INTRODUCTION}

This paper presents the introduction of infographics in two courses during the academic year 20202021. Tasks designed for these two courses were related to:

a) the use of infographics by students to summarize main ideas in some sections of the bachelor's degree thesis and

b) an infographic used by students after organizing information from users' opinions in an affinity map.

An infographic is a visualization that offers a combination of image, text and chart [1]. This enables grouping STEAM competencies in the same task while improving the communication skills of students.

In the experiences described in this paper, images, data and text were combined to reinforce the data included. Moreover, technology was incorporated through infographic applications as a digital support for students in online sessions. Another advantage of an infographic is that visually transmitting important information facilitates the reader's understanding of the message even when it is supported by scientific rigor [2]. If its power to illustrate more complete narratives is considered, the reason why its use has increased in the last decade to communicate many different topics, such as data about health, environment and sciences, is clear [1].

When designing an infographic, the two main features to be considered in its structure are the appearance and the utility [3], for which the content and the narrative are important elements [4]. With respect to the content, it is important to consider the target of the infographic, the main place where it will be displayed and the order of explaining the narrative [2]. The visual aspect will help to communicate the content. For example, icons can help establish the sequence of events; a bigger font size might highlight the main sentences. The narrative will help viewers understand the information being transmitted.

This document is structured as follows. After this introduction, Section 2 defines the methodology designed for each task, including learning objectives and steps to follow in the elaboration of the infographic. Then, Section 3 explains the results obtained in the two tasks, while Section 4 discusses the main conclusions.

\section{METHODOLOGY}

The methodology for each task was organized to consider: 1) the aim of the task in relation to the aim of the subject, 2) instructions for students, 3) criteria for the evaluation, and 4) feedback to students.

\subsection{Task 1: Infographics in the bachelor's degree thesis}

\subsubsection{Aim of the Task}

The task in this course aimed for students to design an infographic for a section in their bachelor's degree thesis. This course could be attended by students from two degree programs, who also might 
have been studying different concentrations in a degree. Therefore, the profiles of students in the course resulted in many different themes in their theses and thus in various types of infographics. The result was that some infographics could be related to a specific law, while others were focused on industry analysis, marketing, finances, service design, or data mining.

The learning outcome from the task was that they could convert a difficult section into an understandable message while maintaining the academic rigor. This was linked with the learning outcome of "oral and written communication", which is among the outcomes defined by the faculty for this subject.

\subsubsection{Instructions for Students}

After explaining what an infographic is, showing different examples adapted to the subject, and using them to illustrate how to create an infographic, some instructions were given to students about the steps to follow in the task (Fig. 1).

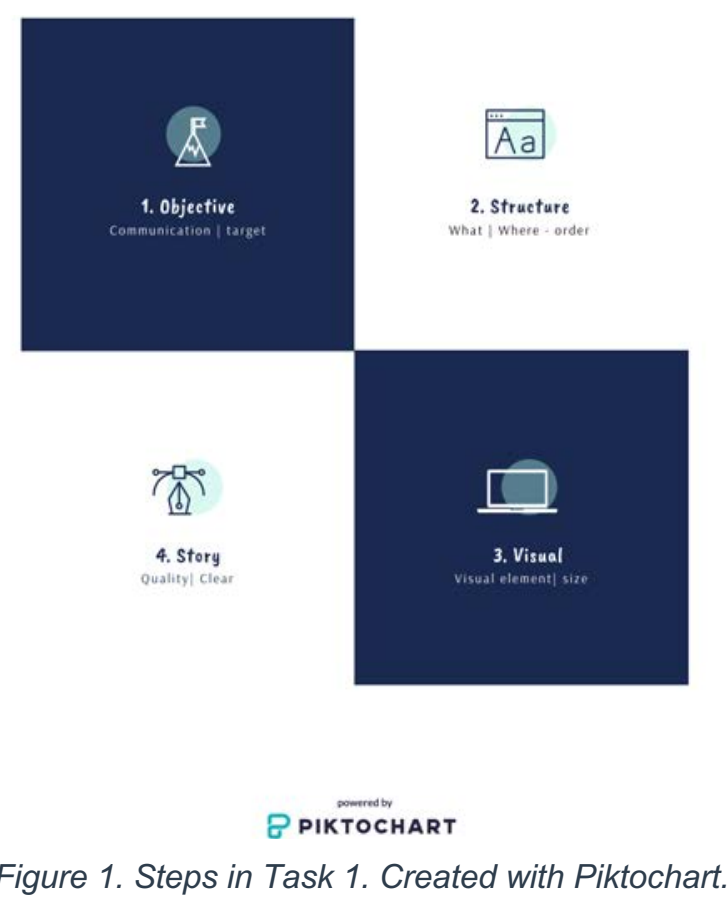

The first step involved selecting the section and information that students would include in their infographic. Then, a title had to be defined for the infographic that would help the reader understand its content. Depending on the type of course, individual advice was offered to every student about the section they should include in the infographic. For example, when a thesis included an extended conceptual section, students were recommended to organize the main ideas in an infographic. Thus, the reader's attention would be focused on the next sections, which would present the student's evidence for their conclusions. However, if students were developing a thesis based on data analytics, the recommendation was to include the infographic in the methods or results sections. In methods, it would help structure the main elements of the section and connect them with the results section. If they included the infographic in the results section, they might summarize the most important ideas visually.

The second step was about the online application used to design the infographic. There are more options all the time, and most of them offer your own design for free (three to five designs). We offered a list to students but let them choose different tools. The list includes Easel.ly, Piktochart, Canva and Visual.ly.

This step also included the structure of the infographic. Here, the student had to select the content in the template and how to organize it, combining text, data visualization, illustrations and images [5]. This step was more focused on the text and the recommendations for students were the same as one uses for a Power Point slide: select carefully the sentences to be included, make them concise and do not copy and paste directly from the written document. 
The third step was focused on the visual of all the elements together, ensuring the final template was appealing. This step involved the combination of colors, the place where each element was included, the size of the letters and the size of the other elements. It is also important to consider that some colors might not be detected by some people. For example, for people with color vision deficiency it is more difficult to differentiate colors like red-green and blue-yellow.

The last step was to check that the infographic told a story such that the order would support the reader's understanding. Including numbers was helpful.

\subsubsection{Criteria for the Evaluation}

Criteria were adjusted to the instructions given to students, and a list with the maximum grade for every element was available for them. As the infographic was part of a longer task, its grade was around $10 \%$ of the total task.

\subsubsection{Feedback to Students}

Feedback to students was individual and was included in the review of the total task.

\subsection{Task 2. Infographics to present results in an affinity map}

\subsubsection{Aim of the Task}

The task in this second course aimed for students to organize users' opinions from a service in an affinity map. After analyzing opinions in social networks and conducting interviews with users, they were to communicate the main results in an infographic. The task met two of the objectives defined by the faculty for this subject: critically synthesize information from a variety of sources and communicate orally and in writing in a foreign language.

An affinity map is "a method for organizing information into key themes" [6]. As there are online tools that offer options equivalent to sticky notes, it is a method that can be adapted to on-campus and online classes. It is a good option when students have no access to a qualitative software but also as a previous step to explain how to create codes with a qualitative software. Students used the affinity map to organize information from customers' reviews in a webpage and after interviews with customers.

The profile of students in the course was not interdisciplinary but multicultural, and they worked in teams. This was very interesting for them because they could share their experience about a service in their countries with classmates in their teams [7].

\subsubsection{Instructions for Students}

After explaining step by step an example like the task they should do, instructions were given to students that included three main phases: choosing a service, collecting reviews and organizing ideas.

The first step was choosing the service whose customer reviews they would analyze. Then, they searched for websites where reviews for the service or companies offering it were available.

The second step was collecting information from reviews for the last two years. The information was saved in an Excel or Word file, which they included in the final report. These files included the words highlighted for the key information.

The third step was to design an affinity map, in which they organized the information collected from customers' reviews. They used an online tool to present the affinity map and included text, visuals, illustrations and numbers. A list with some online applications was offered and they tried some of them, like Piktochart and Miro. As always, we recommended that they search for more options and use the best for them. Fig. 2 shows a template for organizing the main themes found during the review's analysis, dividing keywords between benefits and drawbacks. 

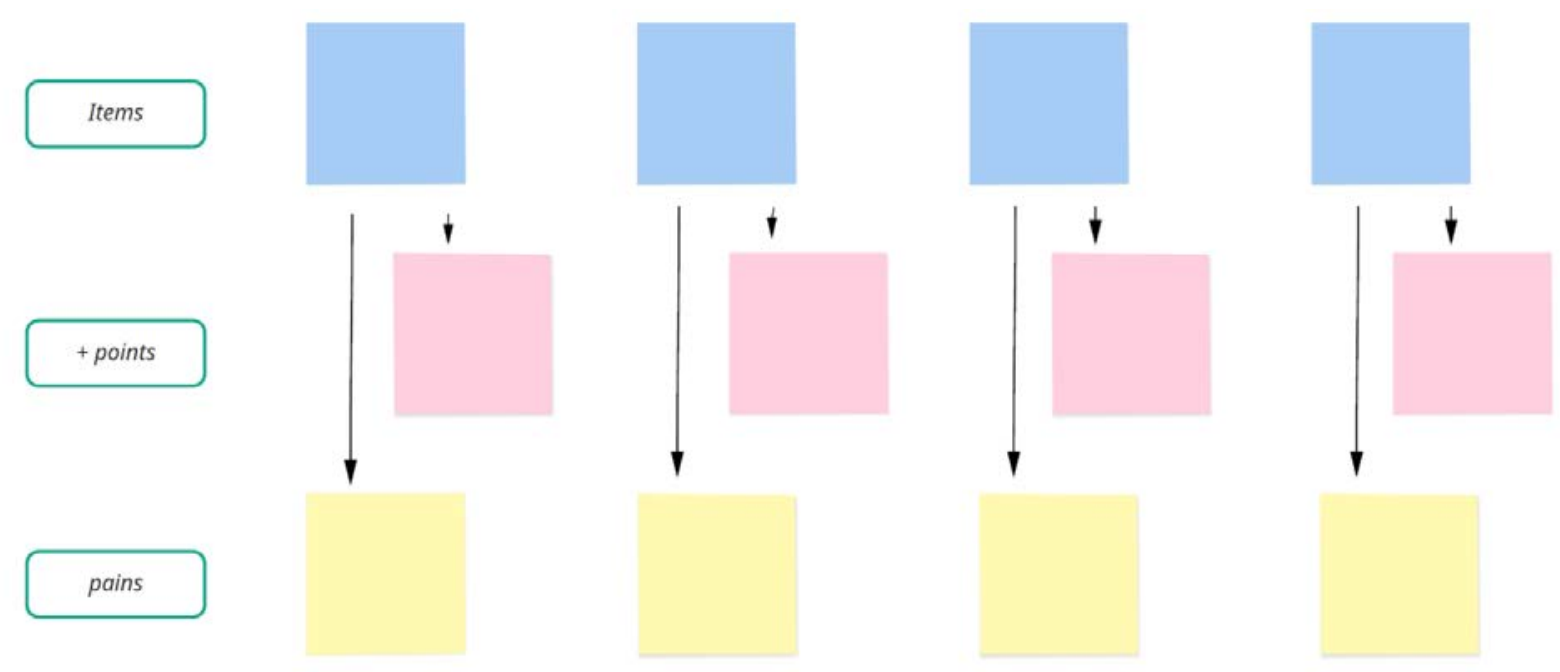

Figure 2. Creating an affinity map with Miro.com.

The last step was to integrate the affinity map into an infographic in order to create a narrative around the affinity map.

\subsubsection{Criteria for the Evaluation}

As in the previous task, criteria were adjusted to the instructions given to students, and a list with the maximum grade for every element was available for them. As the affinity map was part of a longer task, its grade was around $20 \%$ of the total task, and included the collection of information, analysis, and organizing it by themes, positives and negatives. The final task also included the connection with the customer journey, ideas to improve the service and considerations regarding the implementation of improvements [8].

\subsubsection{Feedback to Students}

Feedback to students was individual and was included in the review of the total task.

\section{RESULTS}

Results obtained from the two experiences differed depending on whether the task was carried out individually or as a team, the session was face-to-face or online, and students worked on the same theme or not. Table 1 presents the main results obtained in each task.

Table 1. Results.

\begin{tabular}{c|l|c|c|c|c|c}
\hline \hline Task & \multicolumn{1}{|c|}{ Result } & Yes & No & $\begin{array}{c}\text { Number of degree } \\
\text { programs }\end{array}$ & Participants & Location \\
\hline 1 & Students included tables and figures & $100 \%$ & $0 \%$ & Two & Individual & On-campus \\
\hline 1 & Students included an infographic & $22.22 \%$ & $77.77 \%$ & Two & Individual & On-campus \\
\hline 2 & $\begin{array}{l}\text { Students included affinity map with } \\
\text { online app }\end{array}$ & $65.8 \%$ & $34.2 \%$ & One & Team & Online \\
\hline 2 & $\begin{array}{l}\text { Use of online applications (in the } \\
\text { document) }\end{array}$ & $78.9 \%$ & $21.1 \%$ & One & Team & Online \\
\hline \hline
\end{tabular}

Results indicate that changes which influence digitization are easier to incorporate in a course when students work in teams on the same theme.

Task 1 was conducted on-campus, and although students used their laptops in class, they had to maintain social distance to prevent COVID-19. As they worked on an individual project and theme that was different from other students, working in teams in the class was difficult. 
In contrast, Task 2 was conducted online, and students worked in teams on the same task. Moreover, in this task there was an example with descriptions for each step to follow, and the aim was the same for every student, to design an affinity map based on customers' reviews about a service. Therefore, it was a specific task and creating an example was easier and more useful for students. However, in Task 1 , every student worked on a different thesis, which covered different themes, which made it difficult to create a general example.

The software used by students to design the infographics and affinity maps included templates in Piktochart, Canva, Miro and Microsoft PowerPoint. The interesting result is that even students that did not create an affinity map used these online applications to design figures and tables. Visually, the final documents reviewed by professors had improved when they were compared with previous years.

Including an affinity map in Task 2 resulted in students' development of a more complete final task when compared to previous courses. As the map made students analyze reviews further, they gave more and better ideas to improve the service analyzed.

\section{CONCLUSIONS}

This paper has presented and analyzed the tasks designed for two different courses. The first task was focused on the bachelor's degree thesis, while the second task was centered on creating an affinity map to organize qualitative information from customers' reviews or interviews.

The courses in which the two tasks were conducted were different. In the first case, students who attended the course came from two different degrees and concentrations. The difficulty in this task was to adapt it to many different types of theses. Comparing the two tasks demonstrated that teamwork of students in the second task enabled an easier introduction of a new tool, and to advance in the digitization of the task. This was easier to reach because the course was part of a specific concentration. Therefore, every student worked using the same tool, and teamwork encouraged classmates to adopt an online application to develop the task. The intuitive online tools available also helped in its incorporation by students.

\section{ACKNOWLEDGEMENTS}

This paper was written as part of two innovation and educational improvement projects (PIME) with the support of the Universitat Politècnica de València (Institute of Educational Sciences, ICE). The first project is entitled "Applying STEAM strategies in the areas of Social Sciences and Arts, through ServiceLearning activities", and is coordinated by Professor María de-Miguel-Molina. The second project is entitled "Infographics: Using ICT in the visual and creative representation of teaching content", and is coordinated by Professor María-Angeles Carabal-Montagud.

\section{REFERENCES}

[1] A. Córdoba-Cabús, "Estándares de calidad en el periodismo de datos: fuentes, narrativas y visualizaciones en los Data Journalism Awards 2019," Profesional de la Información, vol. 29, no. 3, e290328, 2020.

[2] T. González-Pacanowski and P. Medina, "Valor comunicacional de la infografía," El Profesional de la Información, vol. 18, no. 4, 413-420, 2009.

[3] J.L. Valero Sancho. La infografía: técnicas, análisis y usos periodísticos. Barcelona, Castellón, Valencia: Publicacions de la Universitat de València, 2001.

[4] M.L. Montes-Rojas, J. García-Gil and D.A. Leija-Román. "Visualización mediática de la ciencia: tipología de la infografía científica de prensa," Revista Española de Documentación Científica, vol. 43, no. 2, e266, 2020.

[5] R. Krum. Cool infographics: Effective Communication with Data Visualization and Design. Indiana \& Canada: Wiley, 2014.

[6] L. Ratcliffe and M. McNeill. Agile Experience Design: A Digital Designer's Guide to Agile, Lean and Continuous. Berkeley, CA: New Riders, 2012. 
[7] B. de-Miguel-Molina, M. de-Miguel-Molina, M. Segarra-Oña and V. Santamarina-Campos. "Encouraging curiosity through STEAM strategies: incorporating the "Science" competence into the Social Sciences field," 13th annual International Conference of Education, Research and Innovation, 2020.

[8] B. de-Miguel-Molina, M. de-Miguel-Molina, V. Santamarina-Campos and M. Segarra-Oña. "Aplicando Design Thinking en una asignatura de FADE," V Congreso de Innovación Educativa y Docencia en Red (IN-RED 2019), 2019. 